\title{
9. Geología de la moral (¿Qué enseña la tierra?)
}

DOI: https://doi.org/10.38017/9789588966458.09

Juan Gonzalo Moreno V¹.

\section{A la memoria de Michel Serres}

Quisiéramos convertir una diferencia casi imperceptible, la ausencia de un acento diacrítico, en un dispositivo colectivo de enunciación, el de aquellos que han sabido integrar la "sabiduría de las rocas" a su discurso y a su forma de vida. Ésta última logia a la que me refiero, encuentra en la tierra su inspiración y es copartícipe de su morfología y de su destino, a decir verdad, como lo somos todos nosotros.

En algunos miembros de la hermandad, el numen proviene de una intuición que asciende seguramente desde los más profundos remezones que esta les ocasiona “¿Quién soy? Un temblor fugaz de nada, que vive en un seísmo permanente. Pues bien, durante un momento de profunda felicidad, la tierra espasmódica se une a mi cuerpo vacilante. ¿Quién soy yo ahora, durante algunos segundos? La Tierra misma. Los dos en comunicación, en amor ella y yo, doblemente desamparados, conjunto palpitante, reunidos en un aura" ¿Es Michel Serres o la tierra misma la que se expresa? Ambos podríamos decir, no en vano al final de este párrafo que cierra el Contrato Natural se pregunta Serres por los derechos de autor: “Debo permitirle que firme?” (1992, pp. 202-203).

1 Ingeniero mecánico y Magíster en filosofía. Profesor asociado de la Escuela de Estudios Filosóficos y Culturales de la Facultad de Ciencias Humanas y Económicas, de la Universidad Nacional de Colombia sede Medellín. Es autor del libro Geosofía y otros ensayos. Ha escrito diversos artículos para libros y revistas especializadas en las áreas de filosofía, estética y lógica. Ha impartido cursos regulares en pregrado y en posgrado sobre la obra de Charles S. Peirce, Michel Serres, Clément Rosset, Edgar Morin, Gilles Deleuze y otros. Actualmente, se encuentra pensionado UNAL. jgmoreno@unal.edu.co 
En otros, una sensibilidad cultivada desde la niñez los pone un comunión vital e intelectual con ella, Levi Strauss cuenta en Tristes Trópicos acerca de los paseos que hacía en su infancia por la meseta languedociana, observando las diferentes capas geológicas que componen el paisaje y las asimila a las que descubre el sicoanálisis y el marxismo en sus respectivos dominios, con el fin de situar su propia labor como etnógrafo:

Entre el marxismo y el psicoanálisis, ciencias humanas, con perspectiva social en un caso e individual en el otro, y la geología, ciencia física aunque también madre y nodriza de la historia, tanto por su método como por su objeto, la etnografía se ubica espontáneamente como en su propio reino (Levi-Strauss, 1988, p. 62).

La tierra se hará, además de madre, hija y amante, como lo proclama Serres en el texto citado, maestra de numerosos miembros de la logia. Françoise Dagognet (2003) clama por unas ciencias de la tierra que inicien una "revolución cultural", afincada en la valoración de las superficies y de las figuras que en ellas se manifiestan “¿Qué puede aportarnos la Geología, ciencia de la tierra, por fuera de sus propios resultados? La definimos como una disciplina mayor e irreemplazable, capaz de iniciarnos en la variedad de las figuras, así como de la manera en que ellas han sido producidas".

Lo interesante aquí es el hecho de que, entre dichas figuras, encontramos: el humilde grano de arena, la huella desvanecida, el crimen irresuelto, la enfermedad mental, la fisonomía del paisaje, la configuración de las ciudades y, para no prolongar las cosas, el drama cósmico: cualquier figura es el testimonio de unos mecanismos de índole geomorfológica que activan "todos los operadores" envueltos en la constitución del Cosmos.

Más adelante, tendremos oportunidad de presentar un variado abanico de discípulos de esta venerable educadora, por lo pronto debemos presentar al más distinguido, díscolo e insufrible de todos: el simiesco profesor Challenger. 
Aunque no se puede negar que el Profesor en algún momento cometió ciertas travesuras que llevaron a su maestra hasta el paroxismo (¿qué discípulo no lo hace?), se puede asegurar que supo aprovechar las lecciones de geología, biología, glosemática, etnografía y otras disciplinas que su mentora le inculcó, y que le hicieron a su vez un maestro algo errático y muy singular.

El caso es que el ya maduro Profesor era amante de la ciencia ficción y supo combinar los materiales de su variado aprendizaje, fraguando una paradójica Tierra-Glacial- Molecular-Anorgámica, en la que se producen ciertos acontecimientos que resultan beneficiosos en algunos casos y perjudiciales en otros. En ocasiones, su creación muestra un rostro apacible y ordenado; otras veces, se torna turbulento y caótico sin poder alcanzar a exhibir un semblante definitivo.

Se cuenta que, en cierta ocasión, fue invitado a dictar una conferencia acerca de la moral en una academia de dudosa reputación (algunas mentes retorcidas le atribuyen su creación a un par de impostores intelectuales), en donde articuló doblemente un memorable y accidentado discurso indirecto libre que fue muy sonado, no solamente por su insólito contenido, sino por la particular expresión del catedrático que parecía estar mezclando muchas voces en una sola voz.

En cuanto al indeciso contenido de su invención, cuenta un testigo de apellido DeLanda, que el profesor, amante de las disyunciones inclusivas, no supo decidir si debía bautizarlo estratoanálisis o esquizoanálisis o rizomática o nomadología o micropolítica o pragmática o ciencia de las multiplicidades.

Como era de esperarse, la lección terminó en desbandada y el profesor acusado de una especie de ronquera animal, se disolvió en medio del evento como un personaje más de Lovecraft, su adorado maestro de ciencia ficción. 
Con el concurso Manuel De Landa (chicano, cineasta, programador, filósofo, chaman, etc.), hemos reconstruido algunos aspectos que se derivan de la ya legendaria conferencia ${ }^{2}$.

\subsection{Antecedentes}

El profesor Challenger, antes de iniciar su fallida carrera de conferencista, se hallaba familiarizado con algunas máquinas de indudable carácter cósmico, se recuerdan con aprensión: la aparatosa máquina perforadora que alcanza "el ganglio nervioso de la tierra" haciéndola aullar, y la reversible máquina desintegradora que termina "esparciendo por el cosmos la interesante personalidad de míster Teodoro Nemor"3.

Dichas experiencias terminaron promoviendo en el malgeniado profesor, el diseño de una de las máquinas más prodigiosas concebida por mente alguna: la máquina abstracta de estratificar.

Preñado de tantas lecturas disímiles, el Profesor sabía mejor que nadie acerca del carácter heterogéneo y múltiple de todo lo que existe, no es de extrañar, entonces, verle haciendo bricolaje a la hora de concebir su creación hecha de piezas y fragmentos provenientes de los más dispares dominios ${ }^{4}$.

La máquina abstracta de estratificar fue construida a partir de elementos y piezas tomados de aquí y de allá, enumeremos algunos de ellos: el Big-Bang, el cuerpo sin órganos de Artaud,

2 Acerca de Manuel DeLanda, Deleuze, las imposturas intelectuales, etc.; ver https://revistareplicante.com/entrevista-con-manuel-delanda/

3 A quien desee conocer más del memorable profesor y su obra, le recomiendo https://www.fabulantes.com/2019/05/el-profesor-challenger-arthur-conandoyle-cientifico-y-aventura-en-tiempos-victorianos/

4 Cuando Levi Strauss define el «bricolaje», propone un conjunto de caracteres bien engarzados: la posesión de un stock o de un código múltiple, heteróclito y sin embargo limitado; la capacidad de introducir los fragmentos en fragmentaciones siempre nuevas; de lo que se desprende una indiferencia del producir y del producto, del conjunto instrumental y del conjunto a realizar (Deleuze y Guattari, 1972, p. 16). 
la glosemática de Hjelmslev, los mitos de los dogones, el doublebind esquizofrénico de Bateson, la estratificación geológica, la genealogía de la moral de Nietzsche, la lógica de lo viviente de Jacob, la etología de las territorialidades de Lorenz, los pliegues anatómicos de Geoffroy Saint-Hilaire, las codificaciones de orden informático, la paleontología de Leroy -Gourhan, etc.

Aun así, la máquina resultó productiva, se sabe que presenta fallos y tropiezos debidos a su carácter heteróclito; sin embargo, ellos terminan haciendo parte de su propio funcionamiento. Ahora bien, lo que produce la máquina en su trepidante y accidentado funcionamiento, es nada más y nada menos que lo real-maquínico:

Todo forma máquinas. Máquinas celestes, las estrellas o el arco iris, máquinas alpestres, que se acoplan con las de su cuerpo. Ruido ininterrumpido de máquinas. «Creía que se produciría una sensación de infinita beatitud si era alcanzado por la vida profunda de cualquier forma, si poseía un alma para las piedras, los metales, el agua y las plantas, si acogía en sí mismo todos los objetos de la naturaleza, maravillosamente, como las flores absorben el aire con el crecimiento y la disminución de la luna» Ser una maquina clorofílica, o de fotosíntesis, o por lo menos deslizar el cuerpo como una pieza en tales máquinas. Lenz se colocó más allá de la distinción hombre-naturaleza, más allá de todos los puntos de referencia que esta distinción condiciona. No vivió la naturaleza como naturaleza sino como proceso de producción. Ya no existe ni hombre ni naturaleza, únicamente el proceso que los produce a uno dentro del otro y acopla las máquinas (Deleuze y Guattari, 1972, pp. 11-12).

Manuel DeLanda, amplio conocedor del pénsum de la difamada academia, le otorga el debido crédito a los fundadores, "según Deleuze y Guattari, los procesos de estratificación tienen lugar no sólo en el mundo de la geología, sino también en cualquier esfera de la realidad"(1996, p. 137). En efecto, el libro en el que se describen dichos procesos es, como todos los libros, un producto de orden geológico 
(...) un libro no tiene objeto ni sujeto, está hecho de materias diversamente formadas y de velocidades diferentes. Cuando se atribuye el libro a un sujeto, se está descuidando ese trabajo de las materias, y la exterioridad de las relaciones. Se está fabricando un buen Dios para movimientos geológicos.

La máquina selecciona partículas (sustancia) a partir de un flujo cualquiera (materia) y las ordena (forma), el resultado es, a su vez, estructurado (forma) en productos estables (sustancia).

El primer nivel se denomina contenido; el segundo, expresión. En el primero, el flujo desordenado de carácter molecular se aglomera; en el segundo, se consolida molarmente. ${ }^{5}$

Esta singular máquina de régimen doblemente articulado es simple, en cambio, el funcionamiento en cada caso es complejo y su descripción se puede encontrar en el registro completo de la exposición de Challenger recogida por Deleuze y Guattari en “Geología de la moral ¿Por quién se toma la tierra?" tercera meseta de su hojaldrado tratado.

La máquina es de régimen oscilatorio, va de la materia a su compactación en estratos que, a su vez, resultan socavados por procesos de desestratificación, se ganan y se pierden territorios sustanciales mediante codificación y descodificación formal.

La materia de estos procesos sin principio ni fin, es la TierraGlacial-Molecular-Anorgámica, transmutada por obra y gracia de la invención del desvanecido profesor en una colosal y palpitante Mecanosfera.

Hay toda una lección de moral en las ocurrencias del inolvidable profesor, recordemos que etimológicamente moral proviene del

5 Así, una doble articulación (repartición y consolidación) transforma estructuras a una escala en otra con una escala mayor. En el modelo propuesto por Deleuze y Guattari, estas dos articulaciones constituyen un diagrama técnico, y es por ello que podemos encontrar esta misma máquina abstracta de estratificación, no solo en el mundo de la geología, sino también en los mundos biológicos y sociales (DeLanda, 2010, p. 41). 
latín moralis, que alude a los hábitos, a las costumbres y no otra cosa es lo que nos enseña el ethos de la Tierra. Ética griega o moral latina, el asunto es comprender "más allá del bien y del mal", la forma como se adquieren los hábitos en cualquier esfera de lo real.

Lo que sucede entre el cuerpo sin órganos de la Tierra y la Mecanosfera cósmica, nos afecta a todos los que vivimos entre sus pliegues, y habría una "sabiduría de las rocas" que sería como un libro abierto (sin sujeto, sin objeto y sin buen Dios); en el seno de los incesantes movimientos geológicos,

(...) existe una «sabiduría de las rocas» de la que podemos obtener una ética que supone la idea de que, en última instancia, nosotros también somos flujos de materia y energía (luz solar, agua, proteínas, etc.). En cualquier momento de estos flujos, cabe distinguir algunas partes más viscosas (endurecidas, estratificadas) que otras. Una ética de la vida cotidiana supondría, en estos términos, encontrar las viscosidades relativas de nuestros flujos y dar fluidez a hábitos endurecidos y hacer más viscosas algunas ideas fugaces; en resumen, encontrar, por medio de la experimentación, la consistencia "justa" de nuestros flujos (DeLanda, 1996, pp. 149150).

¡Qué gran lección! Llevamos en nuestras entrañas los mismos procesos que conforman a nuestra madre-hermana-maestraamante, hay mucho que aprender de ella. Nuestro destino está ligado al suyo de una forma gemelar $y$, a medida en que penetramos en sus secretos-procesos lo hacemos en los nuestros, no somos pasajeros de una errante nave, somos un estrato entre otros sometido a las mismas condiciones y movimientos que los demás, la tierra es una multiplicidad de ellos y allí no somos ni más ni menos que cualquier otro ${ }^{6}$.

6 En el espíritu no lineal de este libro, estas tres esferas de la realidad (geológica, biológica y lingüística) no serán vistas como etapas progresivamente más sofisticadas de una evolución que culminaría en la humanidad como la corona de todo el proceso. Es verdad que un pequeño subconjunto de materiales geológicos (carbono, hidrógeno, oxígeno y otros nueve elementos) constituyen el sustrato necesario para la emergencia de los seres vivos; de igual forma, un 
Comprender el estatuto geológico de todo lo que existe tiene, entre otras consecuencias, la de poner en entredicho la unidad e identidad de todas las cosas y la secuencialidad lineal de las mismas.

\subsection{Maquinismo materialista para principiantes}

1. Hay una única materia dotada de vida no orgánica, lo cual significa que bajo ciertas circunstancias esta se autoorganiza espontáneamente.

2. Hay dos estados mutuamente dependientes bajo los cuales la materia se expresa: molecular y molar.

3. El paso de la materia a su manifestación molecular y de esta a la molar, se opera por medio de dos articulaciones escalonadas. La materia molecular formada a partir de la primera es el contenido, y las estructuras molares resultantes de la segunda forman la expresión.

pequeño subconjunto de materia orgánica (ciertas neuronas en la neo corteza del cerebro humano) proporciona el sustrato necesario para el lenguaje. Pero lejos de ir avanzando en etapas progresivas que irían incrementando el grado de perfección, estas emergencias sucesivas son meras acumulaciones de diferentes tipos de materiales, acumulaciones en las que cada capa sucesiva no forma un nuevo mundo encerrado en sí mismo sino, por el contrario, se resuelve en coexistencias e interacciones de distintos tipos. Además, cada una de las capas acumuladas es animada desde dentro por procesos de auto organización que son comunes a todas las capas. En un sentido muy real, podemos decir que la realidad es un flujo continuo de materia y energía experimentando transiciones críticas, y en las que cada nueva capa de material acumulado enriquece la reserva de dinámicas y combinatorias no lineales disponibles para la generación de nuevas estructuras y procesos. Las rocas y los vientos, los gérmenes y las palabras, son diferentes manifestaciones de esta realidad dinámica y material. En otras palabras, todas estas entidades representan los diferentes caminos por los cuales un flujo único de materia y energía se expresa a sí mismo. De este modo, las páginas que siguen no tienen una crónica del "hombre" y sus logros históricos, sino una reflexión filosófica sobre la historia de la materia y la energía en sus diferentes manifestaciones, así como de sus múltiples coexistencias e interacciones. A los diferentes materiales geológicos, orgánicos y lingüísticos se les permitirá hablar, y el coro de voces resultante nos proporcionará una nueva y más fresca perspectiva de los distintos procesos y acontecimientos que dieron forma a la historia del pasado milenio (DeLanda, 2010, p. 10). 
4. La doble articulación es la condición mínima para la producción de los estratos.

5. Los estratos nunca alcanzan un estado definitivo y su aparente orden jerárquico es transitorio y ajeno a cualquier criterio evolutivo.

6. Los estratos son singularidades en el flujo material, prosperan bajo el hábito (costumbre y ropaje) de la concreción, para disgregarse al cabo del tiempo en la corriente interminable. Los estratos son materia coagulada, la materia es estrato disuelto.

7. Todo lo existente se manifiesta como una multiplicidad de estratos de carácter heteróclito, y su identidad es un asunto de "convención"; es decir, de reunión pasajera y circunstancial.

8. El tiempo deja de ser sucesivo, procede por acumulación estratificada de coexistencias.

9. Fenómenos situados en estratos muy profundos pueden aflorar inesperadamente al lado de otros de más reciente formación, y estratos de patente actualidad pueden hundirse por subducción hasta desaparecer de la vista. Cualquier estrato puede entrar en relación con cualquier en el momento y el lugar oportuno.

10. Nada hay por fuera de la materia y de sus maquinaciones, la inmanencia es el único mandamiento grabado sobre la tabla pétrea de la ley.

Viéndolo bien, Challenger no está solo, es el Gran Maestro de la logia. Demócrito, Epicuro, Lucrecio, Charles Lyell, Charles Darwin, Friedrich Nietzsche, Sigmund Freud, Karl Marx, Louis Hjelmslev, Claude Levi-Strauss, Malcolm Lowry, Michel Foucault, Michel Serres, Françoise Dagognet, Michel Maffesoli, José Ferrater Mora, Nicolai Hartmann, Martin Heidegger, Cornelius Castoriadis, Regis Debray, Pierre Levy, Ezio Manzini, George Kubler, Víctor Turner, Edgar Morin, José Luis Pardo, Umberto Eco, Manuel De Landa, Gilles Deleuze, Félix Guattari y muchos otros; son miembros de la hermandad, es decir, del dispositivo colectivo de enunciación que responde a la pregunta formulada por Deleuze y Guattari ¿Por quién se toma la tierra? 
Todos ellos comparten, de una u otra manera, una visión geológica de lo real. De modo que, sin ánimo de ser exhaustivos y a título de ejemplificación inconclusa, seleccionamos algunas contribuciones con el fin de ofrecer de modo escolar un provisional «Atlas Portátil de Pedagogía Geosófica» ${ }^{7}$.

¿Se ha preguntado cómo considera Freud la psique y la historia?

Nietzsche y Heidegger ya habían ilustrado la naturaleza estratificada, no lineal del tiempo histórico. Los movimientos de la superficie se explican solo si se mira hacia el fondo, allí donde suceden las transformaciones decisivas; los movimientos del fondo son más lentos que los que se verifican en la superficie (...)

Para Freud, la historia es realmente y no míticamente cata-strófica; es decir, que se orienta hacia abajo, puesto que es en los estratos profundos que se "despliega", que despliega realmente su naturaleza no temporal. En el inconsciente (el estrato profundo de la psique y de la historia) todo se conserva, nada se pierde; nada se consume y pasa, sino que todo puede volver a la luz en circunstancias favorables.

En el "espacio" de la historia, todos los recorridos son posibles, avanzando o retrocediendo, hacia abajo, hacia lo profundo, hacia arriba o hacia la superficie.

El espacio de la historia, que todo lo acoge, no conoce las exclusiones del tiempo, la necesidad exclusiva del "antes" y del "después": por eso, es suficiente cambiar la dirección de la mirada para que cambie todo el escenario de la historia (Vattimo, 1994, pp. 222-224).

¿Recibió una educación filosófica en la que los sistemas se suceden como perlas en un collar?

Solo se puede avanzar en estas cuestiones renunciando a la perspectiva estrechamente histórica del antes y después, para

7 Para una adecuada comprensión del término Geosofía, consultar: Moreno, Juan Gonzalo (2006). Geosofía y otros ensayos. Medellín: UNAL. 
considerar el tiempo de la filosofía más que la historia de la filosofía. Se trata de un tiempo estratigráfico, en el que el antes y el después tan solo indican un orden de superposiciones. Algunos senderos (movimientos) solo adquieren sentido y dirección en cuanto atajos o rodeos de senderos perdidos; una curvatura variable solo puede aparecer como la transformación de una o varias curvaturas; una capa o estrato del plano de inmanencia estará obligatoriamente por encima o por debajo respecto de otra, y las imágenes del pensamiento no pueden surgir en un orden cualquiera, puesto que implican cambios de orientación que solo pueden ser localizados directamente sobre la imagen anterior (e incluso en lo que al concepto se refiere el punto de condensación que lo determina supone hora el estallido de un punto, hora la aglomeración de puntos precedentes).

Los paisajes mentales no cambian sin ton ni son a través de las épocas: ha sido necesario que una montaña se yerga aquí o que un río pase por allá, y eso recientemente, para que el suelo ahora seco y llano, tenga tal aspecto, cual textura. Bien es verdad que pueden aflorar capas muy antiguas, abrirse paso a través de las formaciones que las habían cubierto y surgir directamente sobre la capa actual a la que comunican una curvatura nueva. Más aún en función de las regiones que se consideren, las superposiciones no son forzosamente las mismas ni tienen el mismo orden. Así pues, el tiempo filosófico es un tiempo grandioso de coexistencia, que no excluye el antes y el después, sino que los superpone en un orden estratigráfico (Deleuze y Guattari, 1994, p. 61).

\section{3 ¿Ha mirado con cuidado los artilugios que lo circundan?}

Mi mirada recorre las cosas que me rodean: la habitación en que escribo es resultado de la rehabilitación de una construcción que tiene cien años. La instalación de calefacción y la corriente eléctrica han sido introducidas en épocas sucesivas. Los muebles son una variedad de piezas de diferentes edades. Sobre la mesa, que tiene veinte años, se encuentra el teléfono y el procesador de textos. 
El ambiente artificial, al igual que el natural, tienen una estructura geológica. Cada fase histórica sedimenta sus productos, fruto de sus técnicas, de sus formas de organización social, de sus sistemas de consumo, de su cultura. Algo desaparece, otras cosas permanecen y se convierten en sustrato para sedimentos sucesivos.

Las grandes transformaciones, las revoluciones técnicas, sociales y culturales, son, por otro lado, como movimientos telúricos, llevan a modificaciones sustanciales en la disposición de los estratos: las sedimentaciones pueden ser orientadas hacia una condición de existencia completamente diferente de la original, su inalterada materialidad puede ser reconducida a un sistema de sentido y a formas de uso radicalmente nuevas. Así, como el fondo del mar puede convertirse, durante el transcurso de las eras geológicas en la cima de una montaña, lo que la cultura campesina ha producido se ha convertido en algo diferente dentro de la cultura industrial y urbana, y todo ello se convierte en otra cosa diferente en la fase actual (Ezio, 1992, p. 25).

\subsection{Cornelius Castoriadis es un pensador volcánico, su lógica de los magmas y de las estratificaciones da testimonio de ello. ¿No sería justo rescatar un pensamiento tan sugerente como olvidado en nuestro medio?}

El pensamiento de Castoriadis, su obra misma, es coherente con la lógica que impulsa: la lógica de los magmas se encuentra en oposición y complementos a la lógica determinista, puesto que plantea la creación como surgimiento de nuevas determinaciones. Además, el campo del conocimiento -en tanto participa de los atributos que para el ser describe Castoriadis- se encuentra estratificado en capas que se apoyan unas a otras de modo irregular, con comunicaciones entre sí: su obra es al modo de un magma. (...) Se encuentra estratificada en dominios que obedecen a diferentes lógicas y legalidades, y al mismo tiempo cada uno de estos dominios -el psicoanalítico, el filosófico, el político- se apoyan, de un modo no regular, en los otros de manera recíproca. Al mismo tiempo, se comunican entre sí a través de conductos por los cuales circulan ideas, lógicas, imaginación creadora... Su idea al 
postular esta lógica, es que ella suministre los medios para pensar de una manera diferente (que la de una alternativa excluyente y estéril), la antinomia y la solidaridad entre lo lógico y lo que no es lógico, entre la razón y lo no racional. Su objetivo es de oposición al imperialismo de una lógica del entendimiento.

Lo magmático es solidario de la heterogeneidad, sea en el ser, en la psique, en la sociedad, en el dominio mismo del pensamiento. Lo heterogéneo, al igual que la imaginación, corrompe nuestro modo habitual de analizar y pensar lo dado, porque su naturaleza magmática tienta, hace superponer planos que generalmente intentamos mantener separados, ligando lo racional con lo irracional. Lo histórico-social y la psique, la filosofía, la política, el arte, el psicoanálisis, en la obra de Castoriadis, están conectados mediante conductos de lava: la mayoría de sus textos presentan reflexiones sobre estos dominios diversos de lo real, respetando sus lógicas, sus elementos diferenciados, y al mismo tiempo haciendo que del mutuo apoyo y entrelazamiento cada uno sea iluminado de un modo diferente.

Lejos del eclecticismo, Castoriadis pone a prueba la logicidad interna de cada dominio, pero en relación permanente con otras lógicas y elementos, que no le son absolutamente separables ni superponibles. Un claro ejemplo de esto es su postulado que refiere que psique ni sociedad son tanto inseparables como irreductibles. Sus textos son al modo de un magma: un texto sobre política puede derivar naturalmente hacia reflexiones sobre la psique y viceversa. ${ }^{8}$

\section{5 ¿Piensa que la relación entre lo que se ve y lo que se dice es como lo presentan las ilustraciones de las manuales de enseñanza de idiomas?}

Los estratos son formaciones históricas, positividades o empiricidades; capas sedimentarias, hechas de cosas y de palabras, de ver y de hablar, de visible y de decible, de superficies de

8 Franco, Y. (2013). Magma, Cornelius Castoriadis, psicoanálisis, política, filosofía. Biblos. 
visibilidad y campos de legibilidad, de contenidos y de expresiones. Estos últimos términos los tomamos prestados de Hjemlslev. El contenido tiene una forma y una sustancia: por ejemplo, la prisión y los que están encerrados en ella, los presos. La expresión también tiene una forma y una sustancia, por ejemplo, el derecho penal y la «delincuencia» en tanto que objeto de enunciados. Y de la misma manera que el derecho penal como forma de expresión define un campo de decibilidad (los enunciados de la delincuencia), la prisión como forma de contenido define un lugar de visibilidad (el "panoptismo», es decir, un lugar desde el que en cualquier momento se puede ver sin ser visto) (Deleuze, 1987, p. 74).

\section{6 ¿Acaso andaba deambulando Proust por los decadentes salones parisinos con la pica del espeleólogo en la mano?}

Esta sucesión de yo, crea lo que podríamos denominar estructura geológica de la personalidad. Los estados sucesivos del yo se van superponiendo, aunque no resulta de ello un orden inmutable, como el de los estratos de una montaña, puesto que continuamente hay movimientos sísmicos que traen a la superficie ciertas capas antiguas. Hay, pues, una continuidad horizontal del yo en el tiempo, su acumulación biográfica, su historia personal, hecha de saltos mortales, de olvidos y transfiguraciones, difícilmente unidos por la memoria y el cuerpo, pautas de unidad. Y, hay, también, su continuidad vertical en el mismo espacio mnémico-corporal, cuyo límite inferior es la pérdida de la identidad, la inmersión del yo en un disuelto mundo común -koyné biológica de la especie, comunidad informulable de lo inconsciente- y, por fin, la despersonalización (Matamoros, 1988, p. 20).

\subsection{Posiblemente ya no se identifica con ninguna clase social. ¿Conoce el mecanismo de producción de la tribu a la que pertenece?}

En vez de «polis», «thiasis» (en la «thiasis» se aglutinan los que rendían culto a Dionisos. Hay un va-y-ven necesario entre las tribus y la masa. La masa se difracta constantemente en tribus. 
La masa es una entidad autosuficiente (sin fines). La tribu es una sedimentación estadística que se forma y se deforma en filigrana (en la) que la sociabilidad se estructura mediante un dispositivo de doble articulación. La organización de la sociabilidad tiene forma de red. Una red conecta nudos, los nudos de la red serían las tribus. Hay dentro de la masa una segunda articulación que trabaja con el eje de selección y se produce mediante la sedimentación por azar de tribus, y una primera articulación que trabaja con el eje de combinación y se produce mediante la conexión por necesidad de esas tribus. Es la institucionalización o cristalización (Maffesoli, 1990, p. 16).

\section{8 ¿Le gustaría saber algo sobre la composición (bricolaje) de esta fragmentaria "historia" en la que "todos los recorridos son posibles, avanzando o retrocediendo, hacia abajo, hacia lo profundo, hacia arriba o hacia la superficie"?}

El lugar de intentar hacer la «historia» de las formaciones terrestres (los acontecimientos espaciales), según el molde de la Historia de los discursos humanos (occidentales) ¿por qué no, al contrario, hacer una historia de las formaciones discursivas (acontecimientos enunciativos) según el modelo de las formaciones geológicas una «arqueología del saber» (Foucault) una «geología de la moral» (Deleuze Guattari)? (Pardo, 1991, pp. 49-50).

\subsection{Moral material: lo que enseña la tierra}

¡Oh, felicidad, felicidad! He visto nacer la vida, he visto comenzar el movimiento. La sangre de mis venas late tan fuerte que va a romperlas. Tengo ganas de volar, de nadar, de ladrar, de mugir, de aullar. Quisiera tener alas, un caparazón, una corteza, exhalar vapores, tener una trompa, retorcer mi cuerpo, dividirme en muchas partes, estar en todo, diluirme con los olores, desarrollarme como las plantas, correr como el agua, vibrar como el sonido, brillar como la luz, adoptar todas las formas, penetrar en cada átomo, descender hasta el fondo de la materia, -jser la materia!- (Flaubert, 1988). 
El día en que, como San Antonio, como Lenz y como tantos otros, alcancemos el éxtasis después de explorar los estratos más profundos de la materia (la tierra-patria), reconociendo la variedad inconmensurable de los extraños y a la vez familiares hábitats y hábitos que la engalanan ${ }^{9}$, ese día, retornaremos rebosantes de enseñanzas al amparo de la acogedora Gea, "la de anchos hombros," armados con el poder de disolver las fatales obstrucciones escleróticas que nos paralizan, y de hacer más viscosas las volátiles creaciones que intensifican la vida en todas sus manifestaciones.

\section{Referencias}

Dagognet, F. (2003). Una epistemología del espacio concreto. Neogeología (Trad. Gómez, M). Cuadernos de historia de la biología, 22.

DeLanda, M. (1996). Vida no orgánica en Incorporaciones. (Eds. Crary, J y Kwiter, S). Cátedra.

DeLanda, M. (2010). Mil años de historia no lineal. Ed. Electrónica. Deleuze, G. (1987). Foucault. Paidós.

Deleuze, G., y Guattari, F. (1972). El Antiedipo. Barral.

Deleuze, G., y Guattari, F. (1988). Mil Mesetas. Pre-textos.

Deleuze, G., y Guattari, F. (1988). ¿Qué es la filosofía? Anagrama.

Flaubert, G. (1988). La tentación de San Antonio. Siruela.

Franco, Y. (2013). Magma, Cornelius Castoriadis, psicoanálisis, política, filosofía. Biblos.

Maffesoli, M. (1990). El tiempo de las tribus. Icaria.

Manzini, E. (1992). Artefactos. Celeste.

9 "Así, hábitat y hábito son la misma cosa bajo dos puntos de vista, cuya unidad presupone el doble origen del vocablo Ethos" (Pardo, 1991, p. 45). 
Matamoros, B. (1988). Por el camino de Proust. Anthropos.

Pardo, J.L. (1991) Sobre los espacios, pintar, escribir, pensar. Serval.

Serres, M. (1991). El contrato natural. Pre-textos.

Vattimo, G. (1994). Hermenéutica y racionalidad. Norma. 